\title{
Gastric and colon metastasis from breast cancer: case report, review of the literature, and possible underlying mechanisms
}

This article was published in the following Dove Press journal:

Breast Cancer: Targets and Therapy

23 December 2016

Number of times this article has been viewed

\author{
J Carlos Villa Guzmán' \\ J Espinosa' \\ R Cervera' \\ $M$ Delgado ${ }^{2}$ \\ R Patón ${ }^{3}$ \\ JM Cordero García ${ }^{4}$ \\ 'Department of Medical Oncology, \\ ${ }^{2}$ Department of Pathology, \\ ${ }^{3}$ Department of Gastroenterology, \\ ${ }^{4}$ Department of Nuclear Medicine, \\ University Ciudad Real General \\ Hospital, Ciudad Real, Spain
}

\begin{abstract}
Gastrointestinal metastases from breast cancer are not common. We present a 58-yearold female diagnosed with lobular breast cancer some years before whose relapses were gastric and colonic mucosal. Simultaneous metastases are extremely rare. To our knowledge, no cases of initial dual affectation have been reported. The patient also showed gastritis by Helicobacter pylori. Invasive lobular breast carcinoma is the most frequent special type of breast cancer and carries some specific molecular alterations such as loss of expression of E-cadherin. Although underlying mechanisms of metastasization are not entirely known, chemokines as well as inflammatory events seem to be implicated in this process. Interaction between chemokines and their receptors frequently induces cell migration. We hypothesize that $H$. pylori, inflammatory cells, and chemokines may create a favorable environment attracting tumor cells.
\end{abstract}

Keywords: chemokines, gastrointestinal metastases, $H$. pylori, lobular carcinoma

\section{Introduction}

Breast cancer is the most frequent malignancy among women. Approximately 16,000 new cases are diagnosed each year in Spain. The 5-year survival rate is constantly increasing, which implies a growing prevalence in almost all developed countries. Modern adjuvant treatment regimens have yielded a reduction in relapses and higher cure rates.

Relapses have been reported in $30 \%-80 \%$ of patients in spite of surgery, chemotherapy, and radiotherapy, but are rare in early-stage breast cancer. ${ }^{1}$ The most common sites of distant metastases are in bone, liver, lung, and brain.

Lobular carcinoma is less likely to involve the gastrointestinal tract. The incidence of extrahepatic gastrointestinal tract metastases observed in autopsy studies varies from $4 \%$ to $18 \%$, with the most commonly affected organ being the stomach, followed by colon and rectum. ${ }^{2,3}$ Nevertheless, coexisting solitary metastases to both stomach and colon are extremely rare.

\section{Case report}

A 58-year-old female smoker was diagnosed with pulmonary thromboembolism during her first pregnancy, and hypothyroidism and hypertension twenty years ago. She underwent quadrantectomy and lymphadenectomy in May 2006. Pathologic analysis from breast tissue showed a $2.5 \mathrm{~cm}$ invasive lobular carcinoma (ILC), grade III, and 20 of 25 axillary nodes were affected. Immunohistochemical results were as follows: estrogen receptor (ER)-positive, progesterone receptor (PR)-positive, Her-2/NEUnegative, p53 and isolated cells stained for Ki67. Body computed tomography and bone scan were negative for advanced disease.
Correspondence: J Carlos Villa Guzmán Department of Medical Oncology, University Ciudad Real General Hospital, Obispo Rafael Torjia St, 13002 Ciudad Real, Spain

Tel +34 I 696658482

Fax +34926278579

Email jvillaguzman I@yahoo.es
Breast Cancer: Targets and Therapy 2017:9 I-7

(c) (1) (8) ( 2017 Villa Guzmán et al. This work is published and licensed by Dove Medical Press Limited. The full terms of this license are available at https://mwv.dovepress.com/ cc) work you hereby accept the Terms. Non-commercial uses of the work are permitted without any further permission from Dove Medical Press Limited, provided the work is properly attributed. For permission for commercial use of this work, please see paragraphs 4.2 and 5 of our Terms (https://www.doveperess.com/terms.php).
Dovepress

http://dx.doi.org/10.2147/BCTT.S79506 
Adjuvant chemotherapy based on doxorubicin $75 \mathrm{mg} / \mathrm{m}^{2}$ and cyclophosphamide $750 \mathrm{mg} / \mathrm{m}^{2}$ every 21 days for four cycles, followed by four courses of docetaxel $75 \mathrm{mg} / \mathrm{m}^{2}$ every 21 days, was administered in July 2006. Radiotherapy was administered to the remaining breast and drainage areas. Exemestane was initiated in February 2007.

In June 2009, serum markers CEA and CA15.3 began to rise. Chest X-rays, abdominal ultrasound, bilateral mammography, brain magnetic resonance imaging, and positron emission tomography scan did not reveal metastatic disease. A closer follow-up was done. In January 2010, the patient revealed dyspeptic symptoms such as nausea and epigastric pain. She underwent an esophagogastroscopy that demonstrated a granular mucosa with an adenomatous pattern. In the antrum, prepyloric fold did not modify with blowing, and biopsies were taken from all suspected areas (Figure 1). Pathology revealed mucous gastric metastases from a lobular carcinoma of the breast. Immunohistochemical examination was carried out using primary antibodies manufactured by Dako Denmark A/S (Glostrup, Denmark). Mucous gastric metastases were positive for cytokeratin-19 and hormonal receptors (Figure 2). Of note, there was a chronic gastritis caused by Helicobacter pylori. A colonoscopy was performed in February 2009, which showed a polyp that was subsequently excised, and a pathology report showed metastases from a lobular breast cancer, also positive for cytokeratin-7 and hormonal receptors (Figures 3 and 4). Both colonic and gastric biopsies were negative for Erb2/ NEU protein.

Because of this gastrointestinal progression, capecitabine $1,250 \mathrm{mg} / \mathrm{m}^{2}$ every 12 hours (14 days, every 21 ) was initiated. Before treatment, CEA was higher than $100 \mathrm{ng} / \mathrm{mL}(<2.5)$

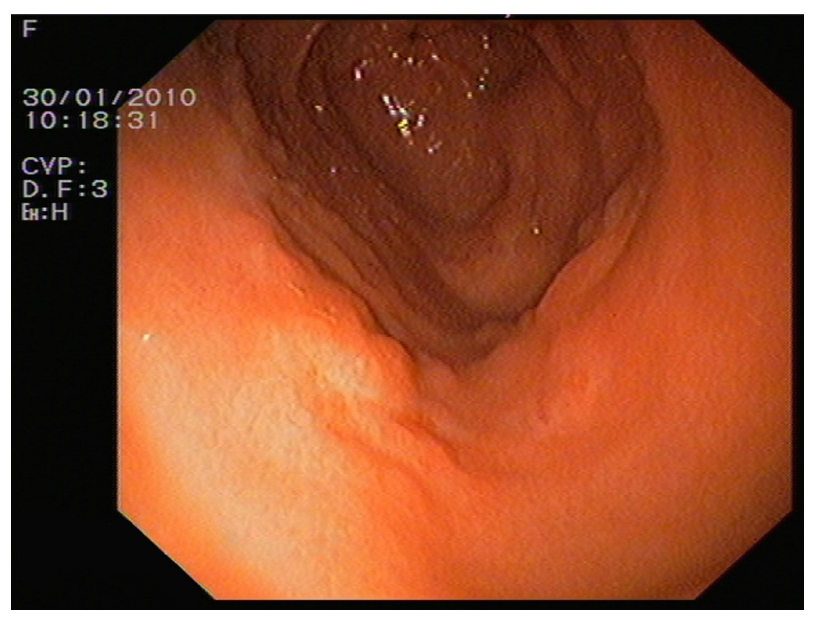

Figure I Endoscopic image of gastric mucosa with granular mucosa with adenomatous pattern. and CA15.3 exceeded $200 \mathrm{U} / \mathrm{mL}(<32.4)$. After six courses of chemotherapy, CEA decreased to $23 \mathrm{ng} / \mathrm{mL}$, while CA15.3 was elevated near the end of chemotherapy and the patient was asymptomatic. A new esophagogastroscopy showed similar findings. A new positron emission tomography scan revealed a hypermetabolic lesion in the second lumbar vertebra. Pancytopenia developed, so a bone marrow biopsy was performed, revealing metastasis in this location. Therefore, a new line of chemotherapy with paclitaxel-carboplatinbevacizumab plus zoledronic acid was started. Despite several chemotherapy and hormone therapy lines consisting of cisplatin-gemcitabine, vinorelbine, liposomal doxorubicin, and other aromatase inhibitors, the patient developed brain metastases and finally died in August 2011.

\section{Discussion}

Single gastric ${ }^{5}$ and colon ${ }^{1}$ metastases and metastases in both locations ${ }^{6}$ from breast cancer have been described, but, to our knowledge, this is the first case of a synchronous spread to stomach and colon as the first and unique initial manifestation of metastatic breast cancer.

The incidence of gastric metastases from breast cancer in long-term series and autopsies ranges between $2 \%$ and $18 \%{ }^{7}$ Lobular breast cancer is the predominant histology found in gastrointestinal tract metastases. The affinity of lobular breast cancer cells for this system is well known. ${ }^{3,8}$ Distant spread may occur many years after the initial treatment for breast cancer. ${ }^{5}$ Other rare sites are gynecologic organs ${ }^{9}$ and the peritoneum. ${ }^{1}$ Ductal tumors tend to metastasize to the liver, the lung, and the brain, ${ }^{5,11}$ although some cases of intestinal metastases have been reported..$^{8,11}$

Symptoms from gastrointestinal metastases are inexpressive. ${ }^{1,5,7}$ Serum marker CA15.3 may be elevated, as in our case. ${ }^{1}$ The endoscopic pattern usually is confounded with a gastrointestinal cancer. The most frequent pattern of spread is diffuse infiltration. ${ }^{12-14}$ The median time to development of metastases is approximately 4 or 5 years. ${ }^{13}$

Metastases to colon could imitate primary colon cancers, ${ }^{1,8}$ may acquire a similar aspect to linitis, ${ }^{15}$ or Crohn's disease, ${ }^{1}$ and may even be a solitary adenomatous polyp. ${ }^{16}$ Our patient had a solitary metastatic localization to an adenomatous polyp in the colon as well as stomach infiltration. Although breast cancer metastasis in stomach and colon may coexist, ${ }^{6}$ it has never been described as the first manifestation of dissemination.

Treatment of gastrointestinal metastases from breast cancer is under discussion. Systemic therapy is the first option, and surgical treatment is considered in cases with 

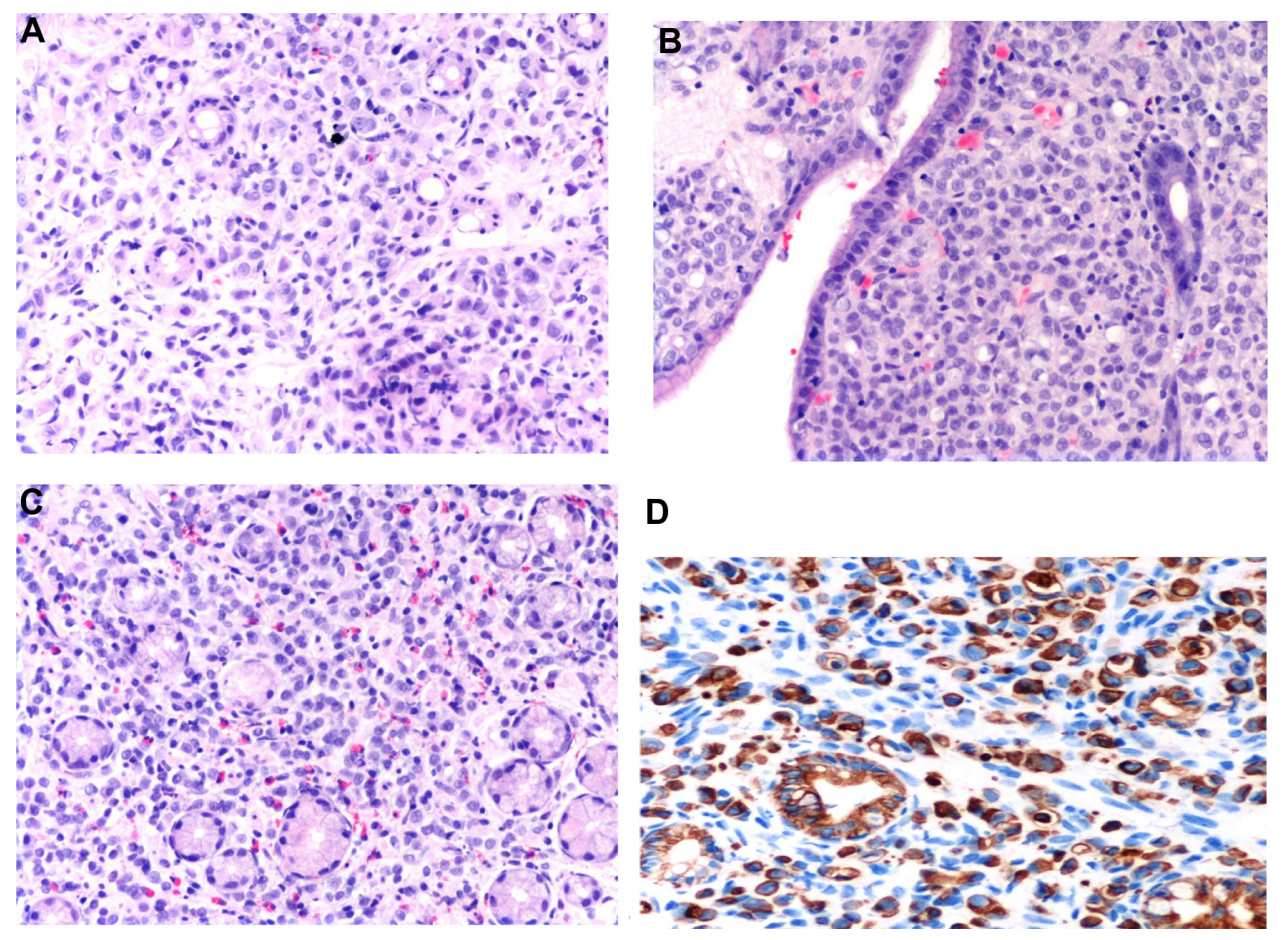

Figure 2 Hematoxylin and eosin staining of the gastric specimen demonstrating strands of invasive cells in the mucosa.

Notes: (A) Lobular breast cancer cells individually dispersed in a single-cell-file pattern around gastric glands (I0× magnification). (B) Discohesive lobular breast cancer cell pattern in gastric specimen (I0X magnification). (C) Gastric mucosa infiltrated by lobular breast cancer cells adopting the typical "Indian file" pattern (I0× magnification). (D) Immunohistochemical staining for cytokeratin CKI9 demonstrating breast cancer cells in gastric mucosa (20× magnification).
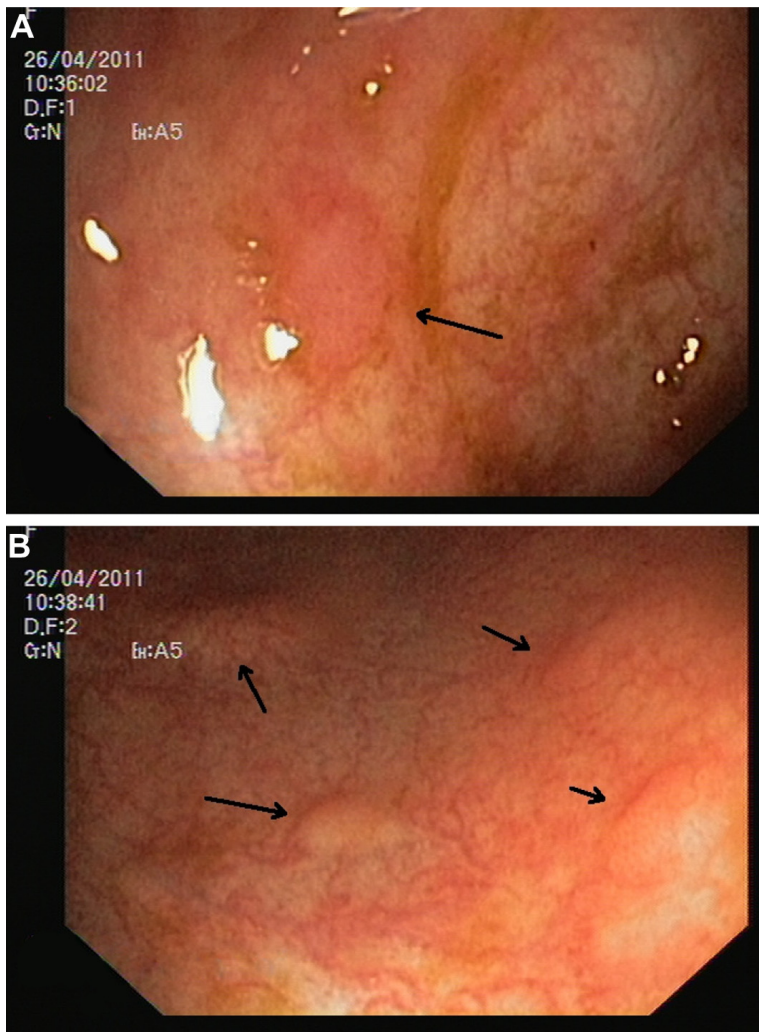

Figure 3 Endoscopic image of colonic mucosa.

Notes: (A) Colonic mucosa erosion (arrow). (B) Several polyps in colonic mucosa (arrows). obstruction or bleeding. ${ }^{3}$ There is a low response rate to chemotherapy in ILC patients..$^{17}$ The median survival rate is 2 years, ${ }^{1,3}$ which implies a poor prognosis, particularly for gastric metastasis. ${ }^{3}$ Hormonotherapy and chemotherapy were used to treat our patient. Surgical treatment was not necessary.

Imaging and endoscopic findings are not enough to differentiate primary from secondary gastrointestinal lesions. ${ }^{3,5}$ Biopsy and pathology are essential for diagnosis. Deep biopsies must be performed with endoscopy, ${ }^{5,7}$ and histology must be compared with the primary breast cancer. ${ }^{18}$ Sometimes, microscopy may differ between primary and metastatic disease, but immunohistochemical analysis may be the only consistent method for differentiating these entities. ${ }^{7}$ Pathologic criteria include infiltration of the serosal, muscular, and submucosal layers by cells, typically in an "Indian file" pattern, ${ }^{11}$ resulting in a signet ring appearance. ${ }^{19}$ ER and PR positivity may suggest breast origin, but these are positive in $32 \%$ and $12 \%$, respectively, of patients with primary gastric cancer. However, the expression of ultimategeneration antibodies against ER $\alpha$ is reliable and useful in differentiating gastric metastasis from breast cancer. ${ }^{5} \mathrm{Her}-2$ extracellular domain (ECD) expression may help in the differential diagnosis of primary gastric cancer vs metastatic 

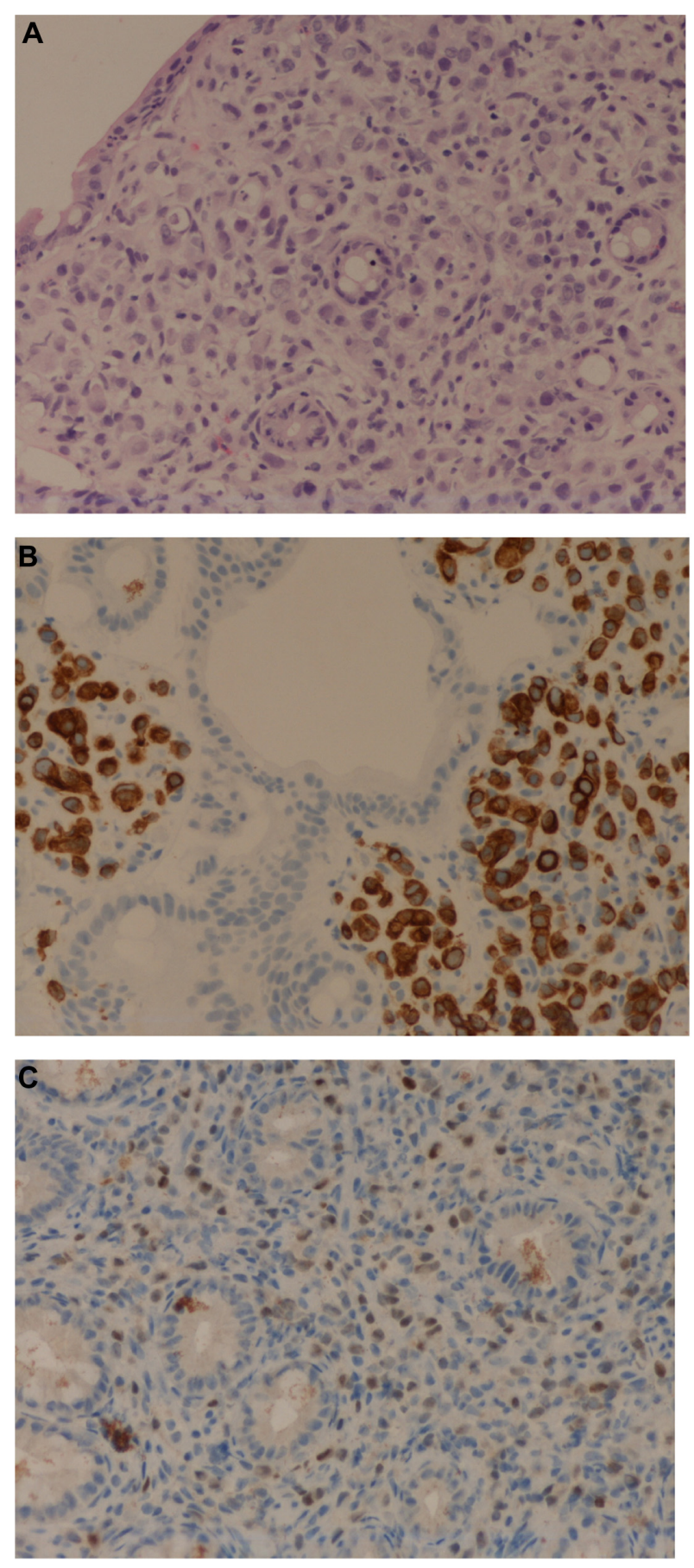

Figure 4 Biopsy of colonic mucosa.

Notes: (A) Hematoxylin and eosin staining demonstrating strands of invasive cells in the mucosa (10× magnification). (B) Immunohistochemical staining for cytokeratin CK7 demonstrating breast cancer cells in colonic mucosa (20x magnification). (C) Immunohistochemical staining for estrogen receptors demonstrating breast cancer cells in colonic mucosa (20× magnification).

breast carcinoma. Absence of ECD is related to lobular breast cancer. Both markers, the presence of $E R \alpha$ and the absence of ECD expression, may reliably distinguish these entities. ${ }^{20}$ In our case, both specimens from stomach and colon were compared with the primary surgical piece removed some years before and were found to match. Breast lesions were characterized by staining for CK7 or CK19 (Figures 2 and 3 ) and hormone receptors. Cytoplasmic positivity for gross cystic disease fluid protein-15 (GCDFP-15) is useful in identifying breast cancer metastasis to gastric mucosa, ${ }^{5}$ but, despite its high specificity $(90 \%)$, its sensitivity is low $(50 \%) .{ }^{3}$ We did not use this immunohistochemical marker. Positivity for ER, PR, CK7, and CDFP15, as well as negativity for CA19-9, CK20, and CDX2, suggest a breast origin of a gastric lesion, ${ }^{3,8,9,11,19}$ particularly in a patient with a past history of breast cancer. Staining for p53 and Erb2/NEU are usually negative, ${ }^{1}$ as in our case.

ILCs are characterized by rather discohesive cells individually dispersed or arranged in a single-cell-file pattern immersed in a fibrous stroma. ${ }^{21}$ This lack of cohesion could be responsible for the development of distant metastases. Most ILCs are of histological grade I/II, express hormone receptors, and do not overexpress HER2 protein like our patient. The pleomorphic variant of ILCs is reported to have an aggressive clinical behavior.

Beta-catenin plays a central role in the ECD/catenin cell-cell adhesion complex, and it may be involved in cellular signaling pathways. Simultaneously, loss of E-cadherin and alpha-, beta-, and gamma-catenin are important steps in the formation of lobular carcinoma in situ, as a precursor of invasive lobular breast cancer. Inactivation of E-cadherin through $C D H 1$ gene mutation, loss of heterozygosity of chromosomal region 16q22.1, and/or gene promoter methylation is an early event reported in more than $95 \%$ of ILCs.22 Moreover, loss or downregulation of CDH1 is associated with tumor dedifferentiation and leads to different events: disruption of the tissue architecture, loss of adhesive properties and proliferation-suppressive function and gain in cellular motility increasing of invasive properties and dissemination of epithelial malignant cells. Of interest, ILC has been reported in families with hereditary diffuse gastric cancer that carry germline inactivation mutations of $\mathrm{CDH} 1 .{ }^{23}$

From an immunohistochemistry point of view, ILCs are not positive for CK20 and express CK7, CK18, thrombospondin (TSP), and integrin alpha-V. ${ }^{31}$ ILC cells also express survivin, cathepsin B, TPI1, SPRY1, SCYA14, TFAP2B, osteopontin, HLA-G, and CHC1.

With regard to genomic considerations, there are some genes overexpressed in ILCs that code proteins involved in cell adhesion like $V W F, E L N, D P T$, and $E M C N$. There is upregulation of $S F R P 1, T G F B R 2$, and IGF1 genes. On the other hand, there are genes overexpressed in classic 
and pleomorphic ILCs implicated in actin cytoeskeleton remodeling/signaling and cell adhesion networks such as ANKDR28 and AFF1. ${ }^{21}$

It is worth mentioning the new role of chemokines in mechanisms of metastasization. Chemokines are a superfamily of chemotactic cytokines present in organs that act as specific modulators in leukocyte migration to sites of inflammation, but are also involved in the initiation and promotion of carcinogenesis by providing growth and angiogenic factors. There are two families that represent the bulk of known chemokines: $\mathrm{CC}$ (the first two cysteines are adjacent to one another) and CXC (the first two cysteines are separated by one amino acid). ${ }^{24}$

Chemokines interact with cell-surface receptors, present in tumor cells, which are members of a large superfamily of seven transmembrane G-protein-coupled cell surface receptors (GPCRs). Interaction between chemokines and their receptors induces migration of cells and mediates inflammatory and tumor cell migration. These chemokines stimulate certain cells to express their receptors by autocrine and paracrine mechanisms. More than 40 chemokines and 18 receptors are currently known. ${ }^{24}$

Chemokine receptors $\mathrm{CXCR} 4$ and $\mathrm{CXCR} 7$ are highly expressed in breast cancer cells, and they are responsible for the chemotaxis to certain target organs such as lymph nodes. CXCL12 (also named SDF-1alpha) and CCL21 (or 6Ckine) bind CXCR4 and CXCR7. ${ }^{25}$ The CXCL12/CXCR4 pathway is implicated in the mobilization, trafficking, and homing of cancer stem cells into metastatic sites. ${ }^{26}$

CXCR4 is implicated in vascularization by initiating and sustaining tumor formation. Signaling through chemokine receptors mediates actin polymerization and pseudopodia formation, favoring invasiveness. CXCR4 also stimulates the production of matrix metalloproteases. ${ }^{27}$

CXCL12 induces synthesis of metalloprotease MT1$\mathrm{MMP},{ }^{27}$ modulates integrin expression, and promotes tumor cell adhesion by attaching cells to extracellular matrix proteins of the basement membrane or to ligands on other cells. ${ }^{28}$ CXCL12 can also regulate tumor cell apoptosis by activating NF- $\kappa \mathrm{B}$, which in turn inhibits tumor necrosis factor- $\alpha$ (TNF- $\alpha$ ) production. Activation of NF- $\kappa \mathrm{B}$ can sensitize cancer cells to CXCL12 stimulation through upregulation of CXCR4 expression. Methylation of CXCL12 promoter in the colonic epithelium favors metastases of tumors in the colon, but further studies are necessary to confirm this hypothesis. Breast tumor cells entering vascular or lymphatic circulation may migrate and adhere mainly to areas expressing CXCL12, therefore migrating to different organs. ${ }^{24}$
Carcinoma cells recruit normal fibroblasts into tumor masses. Fibroblasts produce growth factors, extracellular matrix molecules, and metalloproteases and secrete soluble factors with proinflammatory and suppressant effects. Fibroblasts activate and turn into carcinoma-associated fibroblasts (CAFs). These cells contribute to tumorigenesis and metastasis and are recruited by transforming growth factor beta (TGF- $\beta$ ), platelet-derived growth factor (PDGF), fibroblast growth factor 2 (FGF2), and vascular endothelial growth factor (VEGF) released by tumor cells. In primary tumor and metastatic breast cancer, CAFs produce CXCL12 that promotes tumor growth and enhances angiogenesis through CXCR4 expressed on carcinoma cells and endothelial progenitor cells. ${ }^{29}$ Cytokines and chemokines derived from CAFs induce immune suppression and facilitate invasion and transendothelial migration. Interestingly, both stroma and cancer cells can produce CXCL12.

Furthermore, hypoxia induces CXCR4 expression and CXCL12 production, sensitizes tumor cells to CXCL12 signals, and promotes tumor metastasis. ${ }^{24,28}$ CXCL1 2 attracts vascular endothelial cells and plasmacytoid dendritic cells into the tumor environment, and these cells induce neoangiogenesis through production of IL-8 and TNF- $\beta$. CXCL12 expression seems to be regulated by hypoxia and a hormonetriggered signal pathway. The CXCL12/CXCR4-mediated tumor cell proliferation is regulated by estrogen signaling. In our case, the tumor expressed both ER and PR, which makes this pathway feasible.

It is known that interaction between CCL21 and CCR7 plays a crucial role in lymphocytes homing to secondary lymphoid organs through lymphatic vessels. The mechanism by which CCL21 mediates migration of tumor cells to lymph nodes is similar to the mechanism of the lymphocytes' homing effect. This mechanism may underlie gastric metastasis in $H$. pylori gastritis by acting as an organ with a great inflammatory property similar to lymph nodes in our patient.

Finally, there is a chemokine subgroup growth-related oncogene (GRO): GRO-2 (CXCL-2), GRO-3 (CXCL-3), and interleukin-8 (CXCL-8). These molecules are overexpressed in colonic adenomas and act as angiogenic factors, attract and activate neutrophils, and stimulate endothelial cell migration. GRO-2 (CXCL-2) and GRO-3 (CXCL-3) bind to the receptor $\mathrm{CXCR} 2$, present in neutrophils and endothelial cells, activating them through the NF- $\kappa \beta$ pathway. GRO-2 is upregulated in ER $\alpha$-positive breast cancer patients, and this fact correlates with shorter relapse-free survival. ${ }^{30}$ Colonic metastasis in our patient was found on a polyp. It is possible that the polyp was an adenoma previously, and breast 
cancer cells may have homed over a previous adenoma by this chemokine pathway.

Moreover, there is an interesting role of inflammation. Our patient was diagnosed with gastritis related to $H$. pylori. We hypothesize a possible interaction between the chemokine receptors of circulating breast cancer stem cells and bacterial or inflammatory derived chemokines. It has been reported that there is a relationship between inflammation and tumorigenesis in prostate cancer, where inflammation can induce protumorigenic CXCL16 and CXCR6, ${ }^{31}$ attracting tumor cells. So in our case, it can be hypothesized that chronic inflammation due to $H$. pylori infection may have attracted tumor cells to the stomach and colon because of the action of chemokines. Under favorable circumstances, due to the influence of the same or other cytokines and growing/angiogenic factors, these cells may grow and develop metastatic disease. The degree of cellular infiltration by $H$. pylori seems to be lower in the corpus than in the antrum. ${ }^{50}$ Our patient had gastric infiltration in the antrum, where $H$. pylori was also detected.

Infection with $H$. pylori causes chronic active gastritis, characterized by inflammatory cells infiltrating the gastric epithelial layer and the underlying lamina propria. H. pylori infection is associated with increased rates of expression of CXC chemokines (IL-8, GRO), CC chemokines, normal T-cells, and macrophage inflammatory protein 1-alpha (MIP-1 $\alpha$ ), as well as increased mucosal levels of IL-8. Some of these upregulations are directly controlled by NF- $\kappa B .{ }^{32}$ It is possible that all these cytokines induced by H. pylori may attract and activate tumor cells to home to gastric mucosae.

It is feasible that tobacco consumption may enhance inflammation in gastritis caused by $H$. pylori by inducing GRO and CXCL5 mRNA production. Our patient was a heavy smoker, so this may explain in part the localization of mucosal metastases. Tobacco seems to increase oxygen free radicals from the PMNs and decrease mucus content. Additionally, nicotine may play a role in the induction of CXC chemokine expression, but further studies must be undertaken to confirm this hypothesis.

In colon, metastases may be mediated by receptors of stem cell chemokines in colon bacterial walls. Colon bacteria may produce proteins that mediate inflammation and control metalloprotease production in colonic mucosa in a similar way to $H$. pylori. Molecules influencing polyp production such as GRO2 and GRO3 may contribute to attract tumor cells. It has been reported that human colon epithelial cells release galectin-3, which can activate NF- $\kappa \beta$ in colonic lamina propria fibroblasts and induce the secretion of IL-8 from these cells. ${ }^{33}$

Finally, proteinase-activated receptor (PAR) mediates the cellular actions of serine proteinases. PAR1 and PAR2 are widely distributed in the gastrointestinal tract, and their activation in gastrointestinal inflammation results in proinflammatory reactions mediated by IL-6, IL-8, and prostaglandins. PAR2 activation induces NF- $\kappa \beta$ and AP-1-dependent IL-8 production in association with activation of $\mathrm{p} 38 \mathrm{MAPK}$ and ERK1/2. ${ }^{34}$ This may be another mechanism favoring tumor growing in inflamed mucus.

\section{Conclusion}

Gastrointestinal metastases occur in some cases of lobular breast cancer, but dual infiltration of gastric and colonic regions has not been previously described as the first manifestation of spread. This surprising behavior may involve a mechanism in which chemokines and inflammatory phenomena might be implicated.

The expression of chemokine receptors could determine the type of tumor that metastasizes, whereas the site of dissemination is dictated by expression of the chemokine ligand. Expression of chemokines is passive, and metastatic behavior may be encoded in the primary cancer cell genetic profile.

Further studies are needed to identify the true role of chemokine receptors in metastatic phenomena.

\section{Disclosure}

The authors report no conflicts of interest in this work.

\section{References}

1. Signorelli C, Pomponi-Formiconi D, Nelli F, Pollera CF. Single colon metastasis from breast cancer: a clinical case report. Tumori. 2005;91: 424-427.

2. Kidney CD, Cohen AJ, Butler J. Abdominal metastases of infiltrating lobular breast carcinoma: $\mathrm{CT}$ and fluoroscopic imaging findings. Abdom Imaging. 1997;22:156-159.

3. Ciulla A, Castronovo G, Tomasello G, et al. Gastric metastases originating from occult breast lobular carcinoma: diagnostic and therapeutic problems. World J Surg Oncol. 2008;6:78.

4. Jain S, Fisher C, Smith P, Millis RR, Rubens RD. Patterns of metastatic breast cancer in relation to histological type. Eur J Cancer. 1993;29A: 2155-2157.

5. Pectasides D, Psyrri A, Pliarchopoulou K, et al. Gastric metastases originating from breast cancer: report of 8 cases and review of the literature. Anticancer Res. 2009;29:4759-4764.

6. Malhotra A, Guturu P, Basim MS, Raju GS. A rare case of breast cancer metastasis presenting as linitis plastica of the stomach and colon (with videos). Gastrointest Endosc. 2009;70:552-553.

7. Jones GE, Strauss DC, Forshaw MJ, Deere H, Mahedeva U, Mason RC. Breast cancer metastasis to the stomach may mimic primary gastric cancer: report of two cases and review of literature. World J Surg Oncol. 2007;5:75. 
8. Birla R, Mahawar KK, Orizu M, Siddiqui MS, Batra A. Caecal metastasis from breast cancer presenting as intestinal obstruction. World $J$ Surg Oncol. 2008;6:47.

9. Scopa CD, Aletra C, Lifschitz-Mercer B, Czernobilsky B. Metastases of breast carcinoma to the uterus. Report of two cases, one harboring a primary endometrioid carcinoma, with review of the literature. Gynecol Oncol. 2005;96(2):543-547.

10. Fondrinier E, Guérin O, Lorimier G. [A comparative study of metastatic patterns of ductal and lobular carcinoma of the breast from two matched series (376 patients)]. Bull Cancer. 1997;84:1101-1107. French.

11. Tohfe M, Shami P, Aftimos G, Saade M. Gastrointestinal metastases from breast cancer: a case report. South Med J. 2003;96:624-625.

12. Eo WK. Breast cancer metastasis to the stomach resembling early gastric cancer. Cancer Res Treat. 2008;40:207-210.

13. Taal BG, Peterse H, Boot H. Clinical presentation, endoscopic features, and treatment of gastric metastases from breast carcinoma. Cancer. 2000;89:2214-2221

14. Ueno S, Nakakuma T, Aramaki N, et al. [A case of bilateral breast cancer and metastatic gastric cancer with peritonitis carcinomatosa successfully treated with a combination therapy of S-1 and paclitaxel]. Gan To Kagaku Ryoho. 2009;36(12):2471-2473. Japanese.

15. Taal BG, den Hartog Jager FC, Steinmetz R, Peterse H. The spectrum of gastrointestinal metastases of breast carcinoma: II. The colon and rectum. Gastrointest Endosc. 1992;38:136-141.

16. Wiltz O, O'Toole K, Fenoglio CM. Breast carcinoma metastatic to a solitary adenomatous polyp in the colon. Arch Pathol Lab Med. 1984;108:318-320.

17. Katz A, Saad ED, Porter P, Pusztai L. Primary systemic chemotherapy of invasive lobular carcinoma of the breast. Lancet Oncol. 2007;8:55-62.

18. Alba MA, Piedrafita E, Chivite de León A, Allende L, Sáinz S. [Gastric metastasis of breast carcinoma]. Rev Esp Enferm Dig. 1997;89:647-649. Spanish.

19. López Deogracias M, Flores Jaime L, Arias-Camisón I, et al. Rectal metastasis from lobular breast carcinoma 15 years after primary diagnosis. Clin Transl Oncol. 2010;12:150-153.

20. van Velthuysen ML, Taal BG, van der Hoeven JJ, Peterse JL. Expression of oestrogen receptor and loss of E-cadherin are diagnostic for gastric metastasis of breast carcinoma. Histopathology. 2005;46:153-157.

21. Weigelt B, Geyer FC, Natrajan R, et al. The molecular underpinning of lobular histological growth pattern: a genome-wide transcriptomic analysis of invasive lobular carcinomas and grade- and molecular subtype-matched invasive ductal carcinomas of no special type. J Pathol. 2010;220:45-57.
22. Cleton-Jansen AM. E-cadherin and loss of heterozygosity at chromosome 16 in breast carcinogenesis: different genetic pathways in ductal and lobular breast cancer? Breast Cancer Res. 2002;4:5-8.

23. Carneiro F, Oliveira C, Suriano G, Seruca R. Molecular pathology of familial gastric cancer, with an emphasis on hereditary diffuse gastric cancer. J Clin Pathol. 2008;61:25-30.

24. Andre F, Xia W, Conforti R, et al. CXCR4 expression in early breast cancer and risk of distant recurrence. Oncologist. 2009;14:1182-1188.

25. Zabel BA, Wang Y, Lewén S, et al. Elucidation of CXCR7-mediated signaling events and inhibition of CXCR4-mediated tumor cell transendothelial migration by CXCR7 ligands. J Immunol. 2009;183: 3204-3211.

26. Müller A, Homey B, Soto $\mathrm{H}$, et al. Involvement of chemokine receptors in breast cancer metastasis. Nature. 2001;410:50-56.

27. Bartolomé RA, Ferreiro S, Miquilena-Colina ME, et al. The chemokine receptor CXCR4 and the metalloproteinase MT1-MMP are mutually required during melanoma metastasis to lungs. Am J Pathol. 2009;174: 602-612.

28. Kryczek I, Wei S, Keller E, Liu R, Zou W. Stroma-derived factor (SDF-1/CXCL12) and human tumor pathogenesis. Am J Physiol Cell Physiol. 2007;292:C987-C995.

29. Orimo A, Weinberg RA. Stromal fibroblasts in cancer: a novel tumorpromoting cell type. Cell Cycle. 2006;5:1597-1601.

30. Gupta V, Yeo G, Kawakubo H, et al. Mullerian-inhibiting substance induces Gro-beta expression in breast cancer cells through a nuclear factor-kappaB-dependent and Smad1-dependent mechanism. Cancer Res. 2007;67:2747-2756.

31. Darash-Yahana M, Gillespie JW, Hewitt SM, et al. The chemokine CXCL16 and its receptor, CXCR6, as markers and promoters of inflammation-associated cancers. PLoS One. 2009;4(8):e6695.

32. Kido M, Tanaka J, Aoki N, et al. Helicobacter pylori promotes the production of thymic stromal lymphopoietin by gastric epithelial cells and induces dendritic cell-mediated inflammatory $\mathrm{Th} 2$ responses. Infect Immun. 2010;78:108-114.

33. Lippert E, Falk W, Bataille F, et al. Soluble galectin-3 is a strong, colonic epithelial-cell-derived, lamina propria fibroblast-stimulating factor. Gut. 2007;56:43-51.

34. Yoshida N, Yoshikawa T. Basic and translational research on proteinase-activated receptors: implication of proteinase/proteinaseactivated receptor in gastrointestinal inflammation. J Pharmacol Sci. 2008;108:415-421.
Breast Cancer: Targets and Therapy

\section{Publish your work in this journal}

Breast Cancer: Targets and Therapy is an international, peerreviewed open access journal focusing on breast cancer research, identification of therapeutic targets and the optimal use of preventative and integrated treatment interventions to achieve improved outcomes, enhanced survival and quality of life for the cancer patient.

\section{Dovepress}

View the full aims and scopes of this journal here. The manuscript management system is completely online and includes a very quick and fair peer-review system, which is all easy to use. Visit http:// www.dovepress.com/testimonials.php to read real quotes from published authors. 